\title{
OPTIMAL DOSE OF BASIC FIBROBLAST GROWTH FACTOR FOR LONG-SEGMENT ORTHOTOPIC TRACHEAL AUTOGRAFTS
}

Ryoichi Nakanishi, MD Nobuyuki Nagaya, MD

Takashi Yoshimatsu, MD

Takeshi Hanagiri, MD

Kosei Yasumoto, MD
When a primary anastomosis of the trachea is not feasible, extensive grafting is required. However, despite the use of omental wrapping for revascularization, long-segment tracheal grafts frequently do not maintain structural integrity because of insufficient blood supply. We examined the use of basic fibroblast growth factor for preservation of long-segment tracheal autografts after orthotopic transplantation with omental wrapping in 23 dogs. All animals received orthotopic tracheal transplantation, with 14-ring autografts that occupied a major part of the thoracic trachea, and omental wrapping. The 23 animals were classified randomly into six groups as follows: no treatment (group $I, n=3$ ), topical administration of fibrin glue alone (group II, $n=4$ ), fibrin glue enriched with $1 \mu \mathrm{g} / \mathrm{cm}^{2}$ basic fibroblast growth factor (group III, $n=4$ ), fibrin glue enriched with 5 $\mu \mathrm{g} / \mathrm{cm}^{2}$ basic fibroblast growth factor (group IV, $n=4$ ), and fibrin glue enriched with $10 \mu \mathrm{g} / \mathrm{cm}^{2}$ basic fibroblast growth factor (groups V and VI, each $n=4$ ). The omentum that was used to wrap the autografts was fed by the right gastroepiploic artery in groups $I$ to $V$ and by both the right gastroepiploic artery and splenic artery in group VI. All autografts in groups I and II showed dissolution. Ten of 12 autografts in groups III, V, and VI did not maintain long-term structural integrity. By contrast, all autografts in group IV showed long-term viability, as demonstrated by graft patency, epithelialization, cartilage morphology, and vascularity. We conclude that treatment with fibrin glue enriched with $5 \mu \mathrm{g} / \mathrm{cm}^{2}$ basic fibroblast growth factor in combination with omental wrapping may prolong the viability of long-segment tracheal autografts. (J Thorac Cardiovasc Surg 1997;113:26-36)
W hen a primary anastomosis is not feasible after an extensive resection of the trachea, it is preferable to interpose a substitute trachea than to perform a terminal tracheostomy in the anterior mediastinum to improve the patient's quality of life. ${ }^{1}$ However, prosthetic or ectopic tissue grafts

From the Second Department of Surgery, School of Medicine, University of Occupational and Environmental Health, Kitakyushu, Japan.

Supported by a grant-in-aid (05771003) from the Ministry of Education, Science, and Culture of Japan.

Received for publication Jan. 4, 1996; revisions requested March 28, 1996; revisions received July 9, 1996; accepted for publication July 10, 1996.

Address for reprints: Ryoichi Nakanishi, MD, The Second Department of Surgery, School of Medicine, University of Occupational and Environmental Health, 1-1 Iseigaoka, Yahatanishi-ku, Kitakyushu 807, Japan.

Copyright (c) 1997 by Mosby-Year Book, Inc.

$0022-5223 / 97 \$ 5.00+0 \quad \mathbf{1 2 / 1 / 7 6 3 5 0}$ have achieved only limited success because of failure to reepithelialize and remain patent. ${ }^{2,3}$ By contrast, tracheal grafts with native epithelium can maintain a patent airway and retain elasticity and incorporation. Therefore transplantation of the trachea may, in the future, be the preferred method for reconstruction of extensive tracheal defects.

However, tracheal allotransplantation has two major difficulties, rejection and revascularization of the devascularized tracheal graft. We previously reported that epithelial morphology is valuable in the diagnosis of rejection and reported the efficacy of short-course immunosuppression. ${ }^{4,5}$ We then studied the minimal dose of cyclosporine $\mathrm{A}$ in tracheal allotransplantation. ${ }^{6}$ We also showed that omental wrapping is an effective method to facilitate neovascularization in tracheal autografts. ${ }^{7}$ However, the omental blood supply could not maintain the viability of tracheal autografts longer than $4 \mathrm{~cm}$ in dogs because of the development of ischemia in the 
middle part of the grafts. There is a limit to the length of viable tracheal autografts, even if the blood supply is potentiated by omental wrapping. ${ }^{8}$ Because the ultimate objective of tracheal transplantation is extensive reconstruction, additional study is required to overcome this limitation of tracheal grafting.

Viability of longer tracheal autografts requires enhancement of blood supply. Because basic fibroblast growth factor (bFGF) is one of the most potent promoters of angiogenesis, we chose to investigate its ability to enhance blood supply to these grafts. ${ }^{9}$ This study was undertaken to determine the optimal dose of bFGF for long-segment tracheal autografts after orthotopic transplantation with omental wrapping in 23 dogs. We used autografts to avoid the immunologic complexity of allografts in this experimental design.

\section{Material and methods}

Animals and anesthesia. Twenty-three adult male mongrel dogs weighing from 8.0 to $14.0 \mathrm{~kg}$ were premedicated with an intramuscular injection of ketamine hydrochloride $(20 \mathrm{mg} / \mathrm{kg})$. They were then placed in the supine position and anesthetized with an intravenous injection of pentobarbital sodium $(10 \mathrm{mg} / \mathrm{kg})$. Next, they were intubated orally and connected to a pressure-cycled respirator. Ventilation was done at a tidal volume of $30 \mathrm{ml} / \mathrm{kg}$ and a frequency of 15 breaths $/$ min. Anesthesia was maintained with $50 \%$ oxygen, $50 \%$ nitrous oxide, and $1 \%$ halothane. All animals received humane care in compliance with the "Principles of Laboratory Animal Care" formulated by the National Society for Medical Research and the "Guide for the Care and Use of Laboratory Animals" prepared by the National Academy of Sciences and published by the National Institutes of Health (NIH Publication No. 86-23, revised 1985).

Surgical technique. The animals were positioned for simultaneous right thoracotomy in the third intercostal space and upper midline laparotomy. After laparotomy, an omental pedicle was formed without splenectomy. ${ }^{10} \mathrm{~A}$ standard posterolateral thoracotomy was then done. The intrathoracic trachea was exposed with sharp dissection, and a 14-ring segment of the trachea was identified, three rings above the carina, and removed. A 14-ring segment of the trachea represents almost the entire intrathoracic tracheal length in most dogs. The azygos and brachiocephalic veins were preserved. These 14-ring autografts were then placed in physiologic saline solution at $10^{\circ}$ to $15^{\circ} \mathrm{C}$ for several minutes. A spiral endotracheal tube was positioned in the lower trachea for ventilation after resection. The excised segment was then reimplanted in its original position as an autograft. The upper anastomosis was done first with running 3-0 Prolene polypropylene sutures (Ethicon, Inc., Somerville, N.J.). Next, the membranous portion and two thirds of the cartilaginous portion of the lower anastomosis were sutured similarly. The spiral endotracheal tube was then removed from the
Table I. Experimental design

\begin{tabular}{lcccc}
\hline Groups & $n$ & $\begin{array}{c}\text { Fibrin } \\
\text { glue } \\
(1 \mathrm{ml})^{*}\end{array}$ & $\begin{array}{c}b F G F \\
\left(\mu \mathrm{g} / \mathrm{cm}^{2}\right)^{*}\end{array}$ & $\begin{array}{c}\text { Feeding artery } \\
\text { of omental } \\
\text { flap }\end{array}$ \\
\hline I & 3 & - & - & rGEA \\
II & 4 & + & - & rGEA \\
III & 4 & + & 1 & rGEA \\
IV & 4 & + & 5 & rGEA \\
V & 4 & + & 10 & rGEA \\
VI & 4 & + & 10 & rGEA + SA \\
\hline
\end{tabular}

$r G E A$, Right gastroepiploic artery; $S A$, splenic artery.

${ }^{*}$ All doses were administered topically during operation.

operative field and ventilation was continued via the oral endotracheal tube. The lower anastomosis was subsequently completed.

Groups and drug administration. The 23 study animals were classified randomly into six treatment groups as follows: no treatment (group I, $n=3$ ); topical administration of $2 \mathrm{ml}$ of fibrin glue (Beriplast $\mathrm{P}$, Behring Werke AG, Marburg, Germany; $1 \mathrm{ml}$ fibrinogen/aprotinin, $1 \mathrm{ml}$ thrombin/calcium chloride) (group II, $n=4$ ); topical administration of fibrin glue mixed with $1 \mu \mathrm{g} / \mathrm{cm}^{2} \mathrm{bFGF}$ (KCB-1, $1 \mathrm{mg} / \mathrm{ml}$, Kaken Pharma Inc., Chiba, Japan) (group III, $n=4$ ); topical administration of fibrin glue mixed with $5 \mu \mathrm{g} / \mathrm{cm}^{2}$ bFGF (group IV, $n=4$ ); and topical administration of fibrin glue mixed with $10 \mu \mathrm{g} / \mathrm{cm}^{2} \mathrm{bFGF}$ (groups V and VI, each $n=4$ ) (Table I). The dose of bFGF was calculated as a proportion of the surface area of the autograft, which was derived from the following formula: surface area of autograft $=(a+b) / 2 \times \pi \times c$, where $a$ is the transverse diameter of a cross section of the oral end of the graft, $b$ is the sagittal diameter of the same cross section, and $c$ is the full length of the 14-ring of the graft. One milliliter of thrombin/calcium chloride (Beriplast P) was mixed with the bFGF. This mixed solution and $1 \mathrm{ml}$ of fibrinogen/aprotinin (Beriplast P) were simultaneously administered to the graft. The outer surface of these autografts, including the anastomoses, was soaked circumferentially with the drugs after tracheal autotransplantation.

Omental wrapping. All animals underwent omental wrapping after topical treatment of the autograft. We evaluated the viability of the omental flap that was formed at the beginning of this operation after tracheal autotransplantation. As a result, all the omental flaps maintained viability by means of having a rich blood flow. The omentum used to wrap the autografts was fed by the right gastroepiploic artery in groups I to $\mathrm{V}$ and by both the right gastroepiploic artery and splenic artery in group VI. The omental pedicle was brought up via a diaphragmatic defect into the right thoracic cavity. This pedicle was used to wrap the autograft circumferentially, including each end. The chest and abdominal incisions were then closed in standard fashion. The total operating time was approximately $1 \frac{1}{2}$ hours.

Postoperative management. Animals received antibiotics for the first 7 postoperative days. Bronchoscopic examinations were done weekly after the operation. 


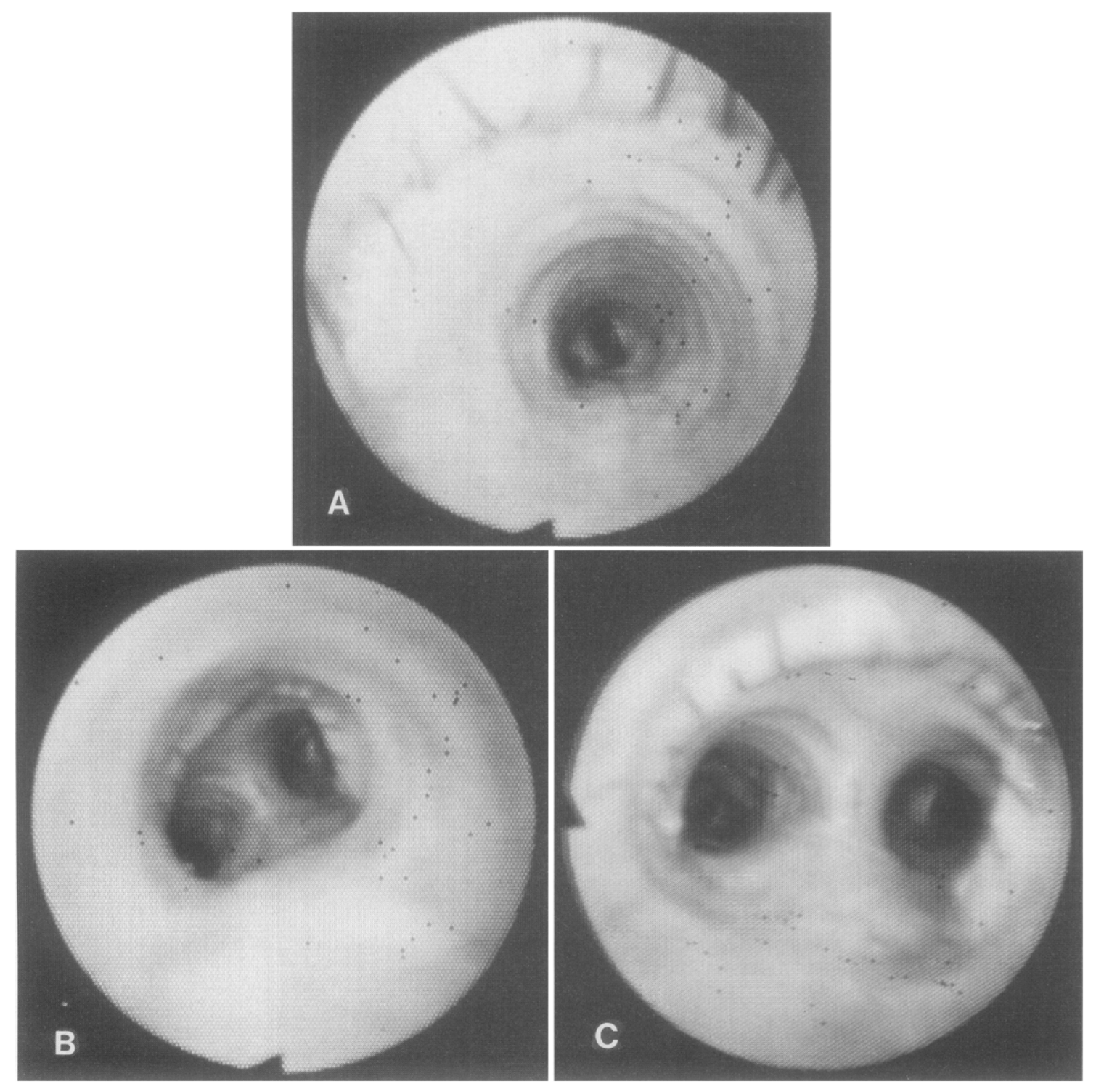

Fig. 1. Bronchoscopic findings in canine tracheal autograft on postoperative day 370 in group IV (dog No. 14). A, Anastomotic site at oral end; $\mathbf{B}$, midportion of graft; $\mathbf{C}$, anastomotic site at caudal end. Graft was covered with glossy mucosa and showed good patency.

\section{Assessment of grafts}

Patency. The patency of the tracheal graft was assessed by calculating the percent patency after the animal had died or at the last bronchoscopic examination while the animal was alive. The percent graft patency was expressed as a proportion of the cross-sectional area of the most stenotic site in the graft to the third tracheal ring above the upper anastomosis in the recipient trachea. The cross-sectional area (CSA) was calculated from the following formula: $\operatorname{CSA}=a / 2 \times b / 2 \times \pi$, where $a$ is the transverse diameter and $b$ is the sagittal diameter. ${ }^{8}$

Histologic assessment. All tissues were fixed in $10 \%$ formalin solution. Microscope slides were made from longitudinal sections of the trachea and adherent omentum and stained routinely with hematoxylin-eosin stain.
Thereafter, all specimens were examined by light microscopy. We attempted to quantify the viability of the orthotopic grafted trachea by subjectively evaluating the epithelial morphology and objectively counting the number of vessels. The morphology of the cartilaginous rings was also assessed inasmuch as this has been reported to be closely associated with effects of bFGF. ${ }^{11,12}$ These assessments were done in a blinded fashion.

EPITHELIAL REGENERATION. Epithelial regeneration was evaluated according to the following grading system: 0 , no epithelium; 1 , single-layer nonciliated epithelium; 2 , multilayer nonciliated epithelium; and 3, normal mucociliary epithelium. ${ }^{5}$ The epithelium of the grafts was assessed as a ratio of the epithelial regeneration score on a microscope slide. 
Table II. Survival and graft status

\begin{tabular}{|c|c|c|c|c|}
\hline Groups & Dog No. & Survival (days) & Cause of death & $\begin{array}{c}\text { Graft status } \\
\text { (at time of death) }\end{array}$ \\
\hline \multirow[t]{3}{*}{ I (control) } & 1 & 9 & Airway stenosis & Dissolution \\
\hline & 2 & 11 & Airway stenosis & Dissolution \\
\hline & 3 & 12 & Airway stenosis & Dissolution \\
\hline \multirow[t]{4}{*}{ II (FG alone) } & 4 & 6 & Airway stenosis & Dissolution \\
\hline & 5 & 9 & Airway stenosis & Dissolution \\
\hline & 6 & 9 & Airway stenosis & Dissolution \\
\hline & 7 & 11 & Airway stenosis & Dissolution \\
\hline \multirow[t]{4}{*}{$\mathrm{III}\left(\mathrm{FG}+\mathrm{bFGF} 1 \mu \mathrm{g} / \mathrm{cm}^{2}\right)$} & 8 & 10 & Airway stenosis & Malacia \\
\hline & 9 & 15 & Airway stenosis & Dissolution \\
\hline & 10 & 21 & Killed & Large granulation \\
\hline & 11 & 215 & Killed & Well healed \\
\hline \multirow[t]{4}{*}{ IV $\left(F G+\right.$ bFGF $\left.5 \mu \mathrm{g} / \mathrm{cm}^{2}\right)$} & 12 & 34 & Killed & Almost healed \\
\hline & 13 & 169 & Killed & Well healed \\
\hline & 14 & 393 & Killed & Well healed \\
\hline & 15 & 673 & Alive & Well healed* \\
\hline \multirow[t]{4}{*}{$\mathrm{V}\left(\mathrm{FG}+\mathrm{bFGF} 10 \mu \mathrm{g} / \mathrm{cm}^{2}\right)$} & 16 & 10 & Infection & Ischemic \\
\hline & 17 & 33 & Airway stenosis & Severe malacia \\
\hline & 18 & 46 & Airway stenosis & Severe malacia \\
\hline & 19 & 375 & Killed & Malacia and granulation \\
\hline \multirow[t]{4}{*}{$\mathrm{VI}\left(\mathrm{FG}+\mathrm{bFGF} 10 \mu \mathrm{g} / \mathrm{cm}^{2}\right) \dagger$} & 20 & 7 & General marasmus & Malacia \\
\hline & 21 & 20 & General marasmus & Malacia \\
\hline & 22 & 70 & General marasmus & Almost healed \\
\hline & 23 & 87 & Airway stenosis & Severe malacia \\
\hline
\end{tabular}

$F G$, Fibrin glue.

*Graft status of dog No. 15 was evaluated at most recent bronchoscopic examination.

$\dagger$ In group VI, an omental flap was fed by blood supplies from both the right gastroepiploic and splenic arteries. In other groups, this flap was fed by the right gastroepiploic artery alone.

CARTILAGE MORPHOLOGY. The morphology of the cartilaginous rings was graded semiquantitatively from 0 to 3 , with 0 indicating severe damage (necrosis area $>70 \%$ of a microscopically visual field); 1 , moderate damage (between $30 \%$ and $70 \%$ necrosis area); 2 , mild damage (necrosis area $<30 \%$ ); and 3 , no damage (normal cartilage).

VESSEL NUMBER. The number of vessels in the submucosa of each graft was counted per high-powered field on a microscope slide. We examined longitudinal sections of the grafts to include both the middle part of the graft and the site of anastomosis, because there is a potential difference in blood flow between these sites. ${ }^{8}$ No attempt was made to distinguish between arteries and veins. The data are presented as the average of three measurements for each graft.

Statistical methods. The probability of survival was calculated by the Kaplan-Meier method. ${ }^{13}$ The significance of the differences in survival rates was computed by the logrank test. ${ }^{14}$ All data as to patency, epithelial regeneration score, cartilage score, and vessel number of the grafts are presented as the mean and standard error. Statistical analysis was done by the paired Student's $t$ test. A $p$ value less than 0.05 was considered statistically significant.

\section{Results}

Bronchoscopic findings. Tracheal autografts that did not receive bFGF (groups I and II) showed dissolution or disintegration of cartilage in the midportion of the graft as early as postoperative day 7 , whereas almost all the autografts that received bFGF in doses greater than $5 \mu \mathrm{g} / \mathrm{cm}^{2}$ (groups IV to VI) maintained the baseline postoperative luminal structure to that time. Two of four grafts in group III showed disintegrations similar to those in groups I and II 7 days after operation. All the autografts in group IV and one in group III ( $\operatorname{dog}$ No. 11) showed gradual decreases in inflammation and demonstrated good patency and intact mucosa after the third postoperative week (Fig. 1). By contrast, inflammation, stenosis, and mucosal changes in the remainder of autografts in group III and in all those in groups V and VI gradually worsened and the grafts eventually showed malacia.

Survival (Table II). All animals in groups I and II, which did not receive bFGF, died of airway stenosis from graft dissolution within 2 weeks after operation. Although we had hoped that all animals that received bFGF would survive for a long period, almost all animals, except for those in group IV, died within 3 months after operation. By contrast, all animals in group IV survived for longer periods and were killed at various times for the purpose of assessing graft viability chronologically. The cumulative percent survival in groups I and II and in 

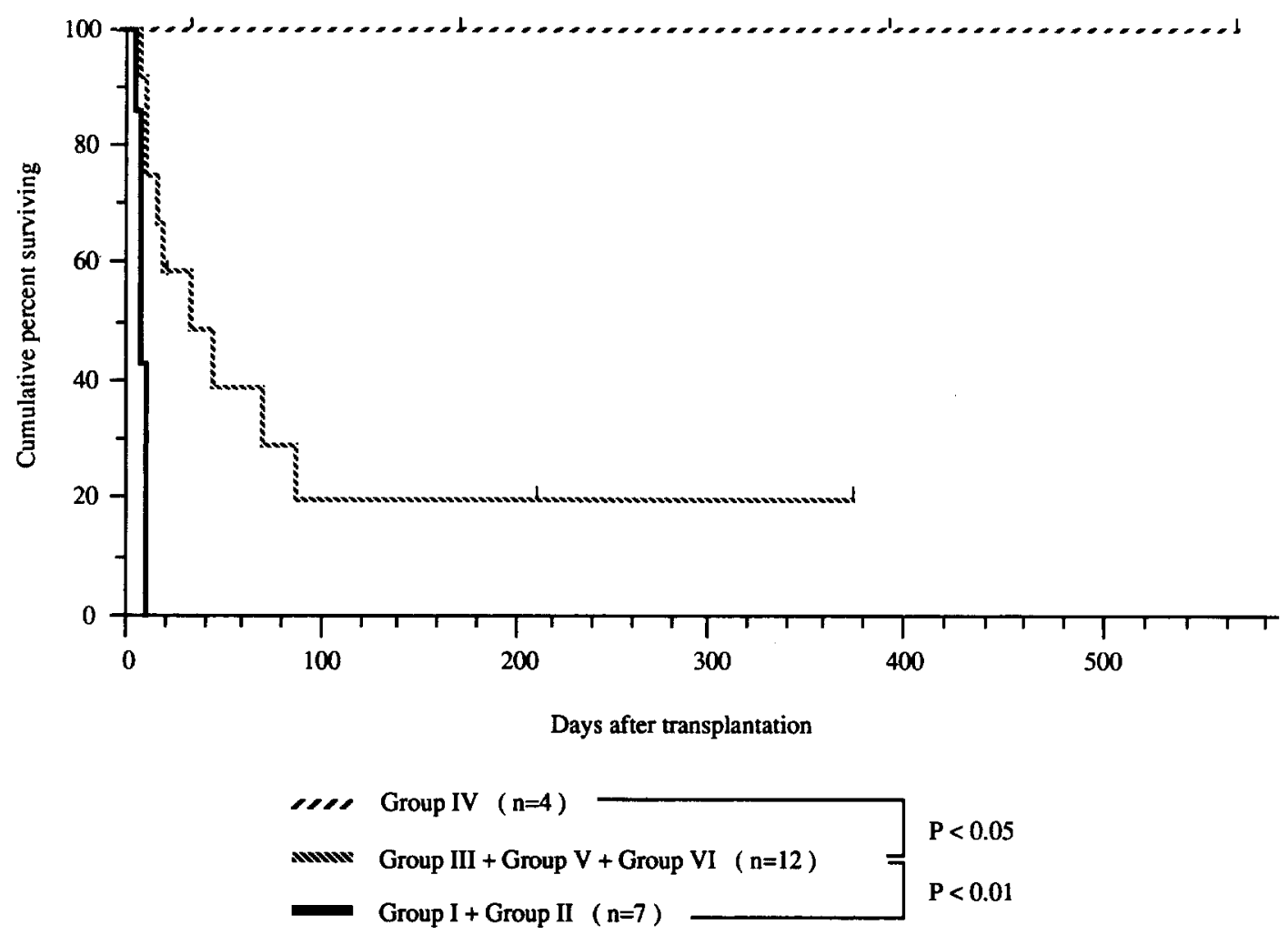

Fig. 2. Cumulative percent survival. Survival in group IV differed significantly from survival in other groups (group IV versus groups I and II, $p=0.0080$; group IV versus groups III, V, and VI, $p=0.0286$ ). Survival in groups III, V, and VI differed significantly from survival in groups I and II ( $p=0.0055)$. Mean survival time of each group was as follows: groups I and II, 9 days; groups III, V, and VI, 33 days. Mean survival time for group IV was not measured because animals were killed.

groups III, V, and VI was significantly less than that in group IV (Fig. 2).

Graft status and percent patency (Table II). When we harvested the grafts, the viable omentum was wrapped firmly around the tracheal autografts in all groups. All the autografts in groups I and II showed dissolution (Fig. 3). The airway was narrowly maintained with connective tissue composed of omentum, although the percent patency of the airway was poor because of loss of luminal rigidity. In groups III, V, and VI (which received bFGF), stenosis of the autograft was seen in nine animals ( $75.0 \%$ ) ( 3 animals from each group). In group III, stenosis of the autografts was caused by malacia, dissolution, or extensive granulation, whereas almost all autografts in groups $\mathrm{V}$ and VI showed stenosis caused by malacia. By contrast, all the autografts in group IV had normal-appearing mucosa and good patency, and almost all were healed (Fig. 4). The graft patencies at each observed time in groups I and II were significantly worse than those 7 days after transplantation. A milder progressive loss of graft patency across these times was also seen in groups III, V, and VI. However, there was no difference in patency at any point in group IV. The average graft patency at all points was significantly better in group IV than in group I or II (Fig. 5).

\section{Histology}

Epithelial regeneration. All animals in groups $\mathbf{I}$ and II and three animals in group III showed no epithelial regeneration in the autografts. By contrast, one autograft in group III and all those in group IV demonstrated normal mucociliary epithelium. Two animals in group V and three in group VI showed some reepithelialization of the autografts. These autografts showed partial restoration of the epithelium, which was almost covered by a single layer of nonciliated epithelium. The epithelial regeneration score of the grafts in group IV was significantly better than those in the other groups (Table III). 

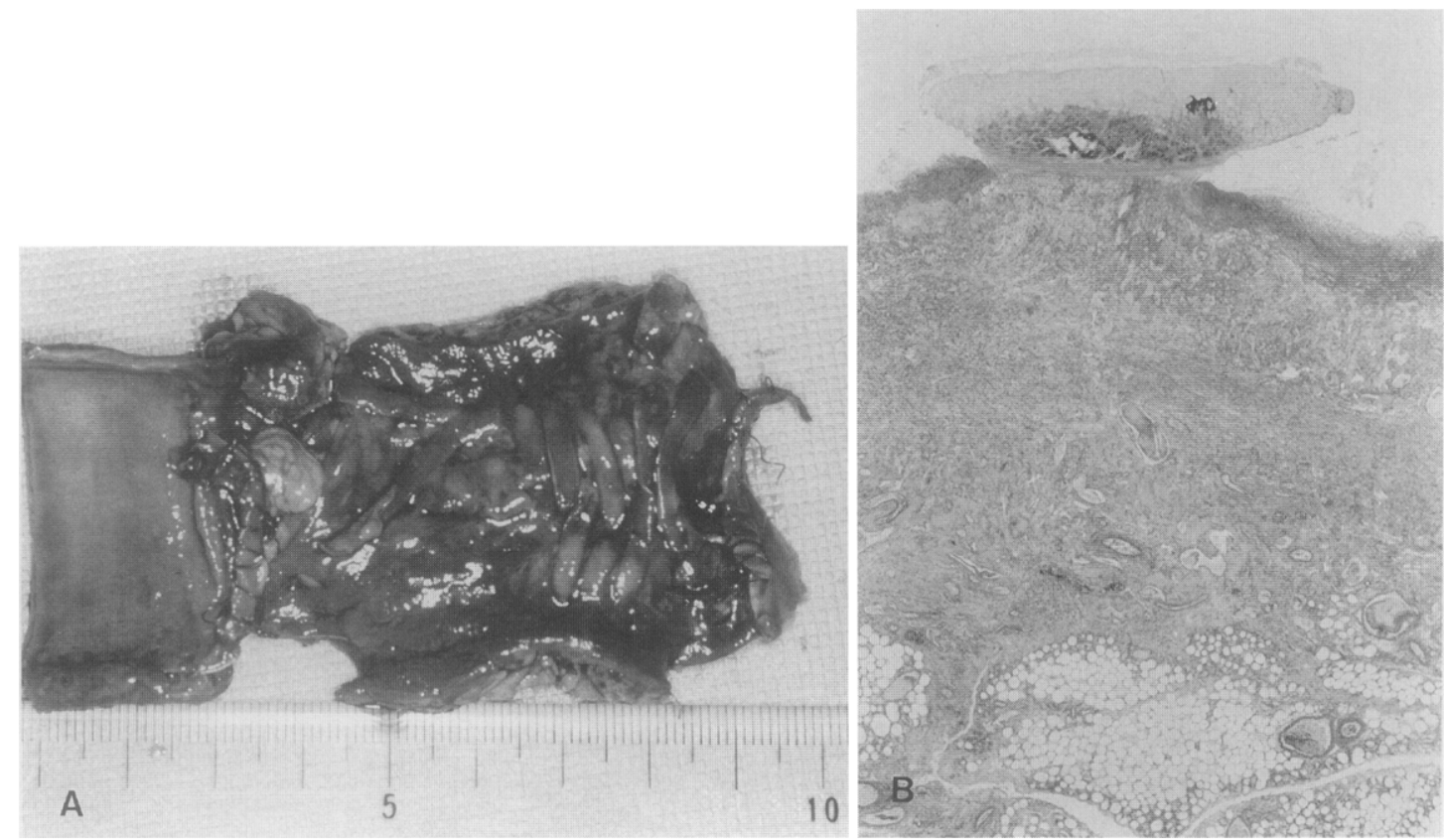

Fig. 3. Canine tracheal autograft on postoperative day 12 in group I (dog No. 3). A, Gross findings; B, histologic findings (hematoxylin-eosin stain; original magnification $\times 12.5$ ). Autograft is necrotic and cartilage is disintegrated or dissolved. Epithelial regeneration is not seen.

Cartilage morphology. In groups I and II, the cartilage of the autografts was either necrotic or absent. Three of four autografts in group III showed the same findings as those in groups I and II. The cartilage of the autograft in one animal of group III (dog No. 11) maintained its structural integrity. The autografts in group IV not only demonstrated viability but also showed areas of proliferation. In the autografts of groups V and VI, hyperplasia of the perichondrium and proliferation of cartilage was often seen on the adventitial side of the grafts. The cartilage score of grafts in groups IV and VI was significantly better than that of group I or II (Table III).

Vessel number. In groups I and II, the autografts were so necrotic that few vessels were seen. Three autografts in group III had a few vessels. By contrast, one autograft in group III and all those in group IV demonstrated many vessels and an intact interstitium. All the autografts in groups V and VI had some interstitial damage as evidenced by proliferation of granulation tissue, fibrosis, and hemorrhage. Consequently, these autografts showed few intact vessels. Autografts in group IV demonstrated significantly higher numbers of vessels than those in all other groups, except for group VI (Fig. 6).

\section{Discussion}

Omentum is capable of revascularizing ischemic tissues and maintaining their viability without an apparent arterial blood supply, perhaps because the lipid fraction of omentum has specific angiogenic factors. ${ }^{15}$ Omental wrapping has been proved to allow successful airway revascularization and improve bronchial healing in canine lung transplantation models. ${ }^{16}$ In clinical lung transplantation, however, ischemic airway complications remain despite the use of omental wrapping. ${ }^{17}$ Omentum may, therefore, have a limited ability to revascularize. We previously demonstrated an inadequate blood supply from the omentum to tracheal transplants. ${ }^{8}$ Devascularized tracheal transplants require enhancement of the omental revascularization for prolonged graft survival.

A few investigators have recently reported successful long-segment tracheal reconstruction with use of a composite thyrotracheal transplant. ${ }^{18}$ This approach includes a technique for microvascular anastomoses to preserve peritracheal microcirculation and can maintain its natural hemodynamics. Therefore these long-segment tracheal transplants can remain viable without further enhancement of local vascularization. However, this approach is so 

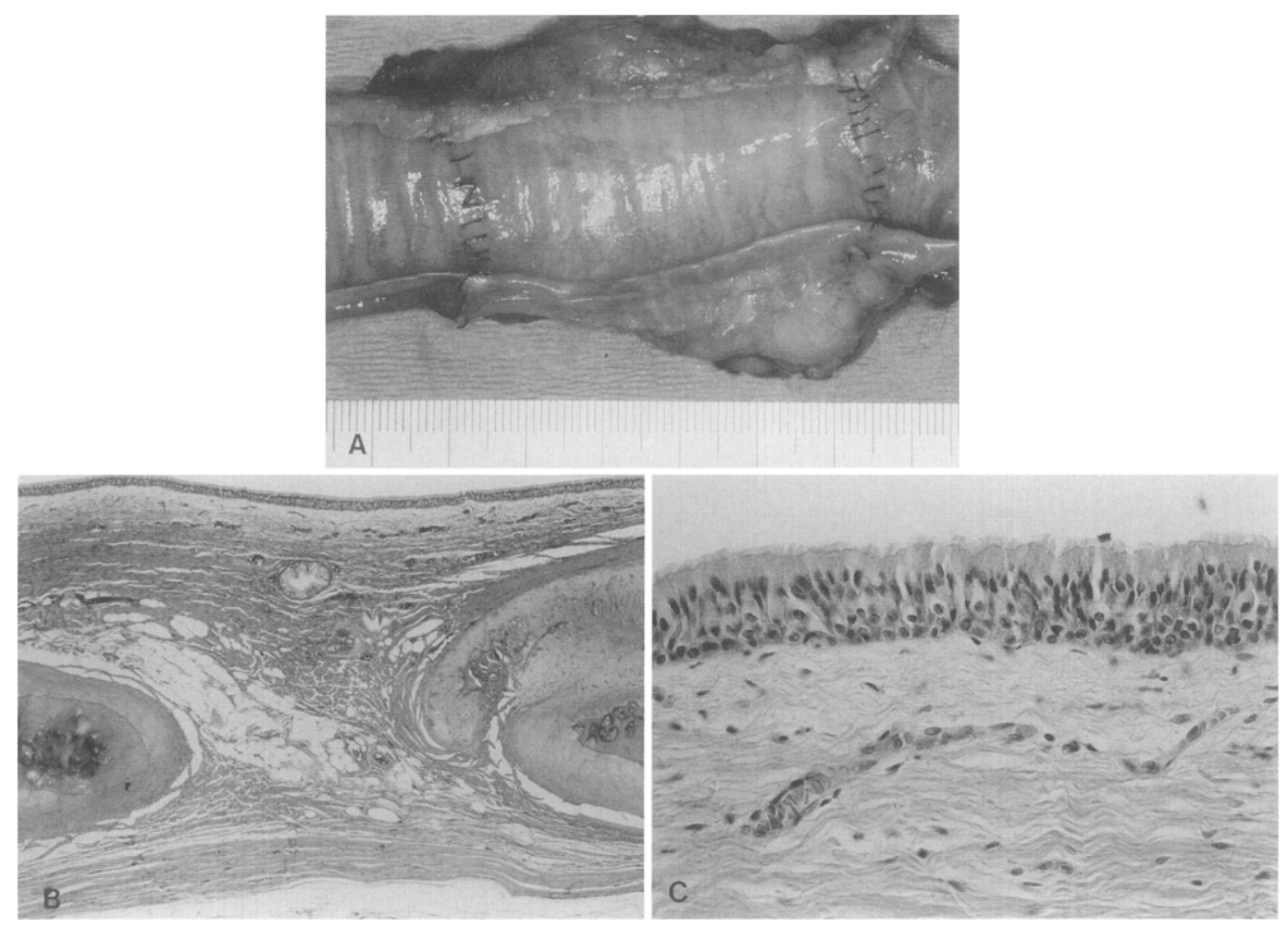

Fig. 4. Canine tracheal autograft on postoperative day 393 in group IV (dog No. 14). A, Gross findings; $\mathbf{B}$, histologic findings (hematoxylin and eosin stain; original magnification $\times 12.5$ ); $\mathbf{C}$, epithelial morphology (original magnification $\times 100$ ). Tracheal continuity is restored by autograft. Many vessels and proliferation of submucosal connective tissue and cartilage are seen, but narrowing of graft is not seen. Epithelium is almost completely restored $(89.1 \%)$ and is composed of nearly normal mucociliary epithelium (epithelial regeneration score $=2.24$ ).

technically demanding that it may not be routinely available.

In a medical approach to this problem, Inui and associates ${ }^{19}$ have demonstrated that prostacyclin improves the microcirculation of bronchi after lung transplantation. This agent is a natural prostaglandin with a strong vasodilatory action. Therefore systemic administration of this agent results in improvement of bronchial blood flow and may reduce the incidence of bronchial complications after lung transplantation. However, administration to either the donor or recipient alone did not lead to such favorable results. Although the effects of this agent are encouraging, prostacyclin treatment alone is unlikely to achieve long-term survival of devascularized trachea.

Recently a new approach that uses promotion of angiogenesis itself has been reported. Several vascular growth factors have been isolated and shown to induce angiogenesis. The most well described of these, bFGF, is a protein of approximately 17,000 $\mathrm{Da}$ molecular weight and has been isolated from bovine pituitary tissue..$^{20}$ It is a potent angiogenic factor in vitro ${ }^{9}$ and in vivo ${ }^{21,22}$ and is mitogenic and chemotactic for both fibroblasts and endothelial cells. $^{23}$ This factor, which stimulates new blood vessel growth and fibroblast proliferation, leads to the formation of granulation tissue and is associated with reepithelialization. ${ }^{24}$ Moreover, bFGF applied to freshly injured cartilage promotes cartilage repair. ${ }^{12}$ We used bFGF in these experiments because it both enhances local revascularization and has positive effects on epithelium and cartilage, which are important components of tracheal transplants.

There have been only three prior studies on tracheal revascularization with $\mathrm{bFGF}$. The role of bFGF in revascularization of rabbit tracheal autografts was first reported by Olech and associates ${ }^{25}$ in 1991. They applied bFGF in a dose of $10 \mathrm{ng}$ to rabbit tracheal autografts without any notable ef- 


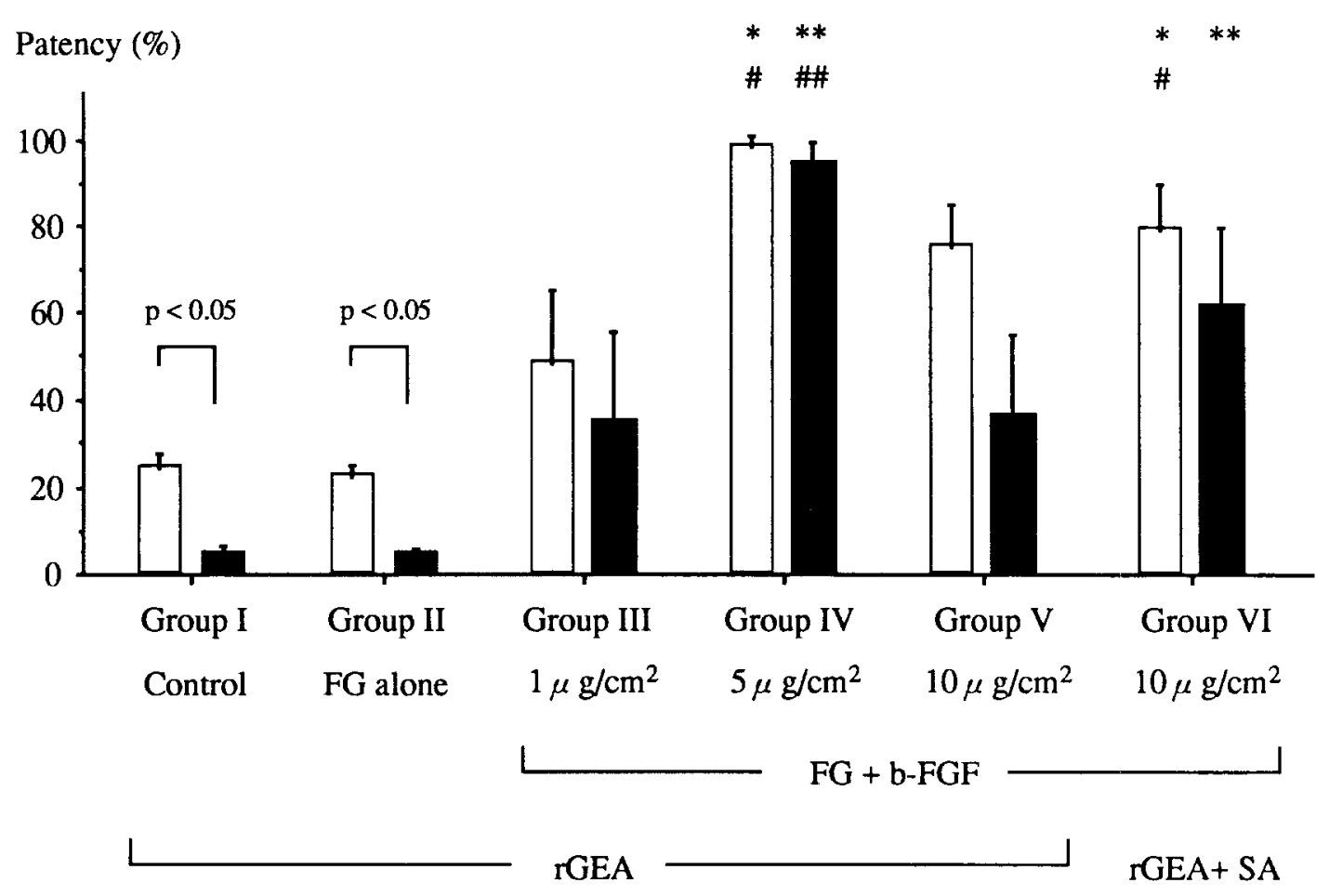

Fig. 5. Average graft patency. Data are presented as mean plus or minus standard error. ${ }^{*},{ }^{* *}, p<0.05$ versus group I at that time; \#, \#\#, $p<0.05$ versus group II at that point (graft patency 7 days after transplantation: groups I versus IV, $p=0.0009$; I versus VI, $p=0.0177$; II versus IV, $p=0.0009$; II versus $\mathrm{VI}, p=0.0305$, and graft patency at observed end-point: groups I versus IV, $p=0.0055$; I versus VI, $p=$ 0.0124; II versus IV, $p=0.0004$ ). Autografts in group IV showed good patency throughout entire postoperative course and were significantly superior to those in groups I and II, which did not receive bFGF. $F G$, Fibrin glue; $r G E A$, wrapping of omental flap fed by right gastroepiploic artery; $r G E A+S A$, omental wrapping fed by blood supplies from both right gastroepiploic and splenic arteries. Open bars represent graft patency 7 days after transplantation; solid bars represent patency at observed end-point.

Table III. Semiquantitative score of graft histopathologic findings

\begin{tabular}{lcc}
\hline \multicolumn{1}{c}{ Groups } & Epithelial regeneration score & Cartilage score \\
\hline I (control) & 0 & 0 \\
II (FG alone) & 0 & 0 \\
III (FG + bFGF $\left.1 \mu \mathrm{g} / \mathrm{cm}^{2}\right)$ & $0.56 \pm 0.56$ & $0.75 \pm 0.75$ \\
IV (FG + bFGF $\left.5 \mu \mathrm{g} / \mathrm{cm}^{2}\right)$ & $2.08 \pm 0.45^{* \dagger}$ & $2.75 \pm 0.25^{* \dagger}$ \\
V (FG + bFGF 10 $\left.\mu \mathrm{g} / \mathrm{cm}^{2}\right)$ & $0.19 \pm 0.16$ & $1.75 \pm 0.48 \dagger$ \\
VI (FG + bFGF $\left.10 \mu \mathrm{g} / \mathrm{cm}^{2}\right) \neq$ & $0.18 \pm 0.07$ & $1.75 \pm 0.25^{*} \dagger$ \\
\hline
\end{tabular}

Data are presented as mean plus or minus standard error of the mean. $F G$, Fibrin glue.

${ }^{*} p<0.05$ versus group I.

$\dagger p<0.05$ versus group II (epithelial regeneration score: groups I versus IV, $p=0.0431$; II versus IV, $p=0.0431$; cartilage score: groups I versus IV, $p=$ 0.0153 ; I versus VI, $p=0.0377$; II versus IV, $p=0.0016$; II versus V, $p=0.0354$, II versus VI, $p=0.0060$ ).

$\ddagger$ Group VI received an omental wrapping fed by blood supplies from both the right gastroepiploic and splenic arteries in contrast to other groups in which this flap was fed by the right gastroepiploic artery alone.

fects. On the other hand, Mayer and colleagues ${ }^{26}$ demonstrated that a $400 \mathrm{ng}$ dose of bFGF could promote the viability of heterotopic rat tracheal isografts. Albes and associates ${ }^{27}$ showed that $2.5 \mu \mathrm{g}$ bFGF improved revascularization of heterotopic rabbit tracheal autografts. Although these studies are not clinically applicable because of the use of a heterotopic transplantation model, they suggest that adequate doses of bFGF may prolong graft survival. Research on the dose effect of bFGF has been 


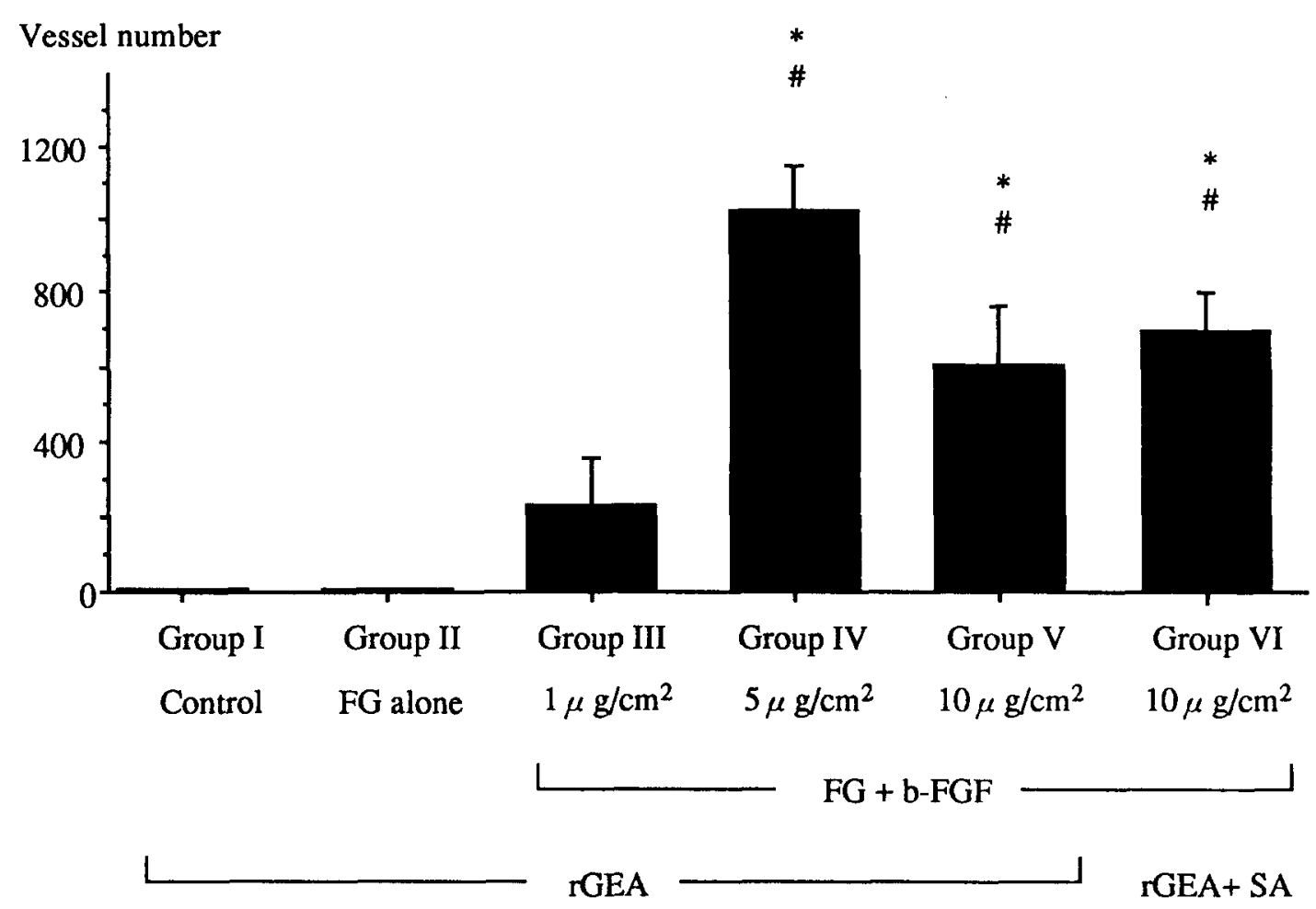

Fig. 6. Number of blood vessels in tracheal grafts. Data are presented as mean plus or minus standard error. ${ }^{*}, p<0.05$ versus group I; \#, $p<0.05$ versus group II (groups I versus IV, $p=0.0141$; I versus V, $p=0.0210$; I versus VI, $p=0.0011$; II versus IV, $p=0.0141$; II versus V, $p=0.0433$; II versus VI, $p=$ 0.0006). Autografts in group IV showed highest number of vessels and were significantly superior to those in all groups except for group VI. Vessel numbers of groups V and VI differed significantly from those of other three groups, except for group IV, but did not differ significantly from each other. $F G$, Fibrin glue; $r G E A$, wrapping of omental flap fed by right gastroepiploic artery; $r G E A+S A$, omental wrapping fed by blood supplies from both right gastroepiploic and splenic arteries.

evaluated in other organs. In a bone fracture model of rats, Kawaguchi and colleagues ${ }^{28}$ demonstrated that treatment with bFGF caused a dose-dependent acceleration of callus formation. Application of 50 $\mu \mathrm{g}$ bFGF to the impaired fibula significantly increased the volume and mineral content of the callus when compared with application of less than $10 \mu \mathrm{g} .{ }^{28}$ That study gives the impression that higher doses of bFGF have more favorable effects. However, it is possible that high-dose bFGF may also promote negative effects such as proliferation of granulation at the anastomotic site of the trachea. Therefore it is important to determine the optimal dose of bFGF required to promote revascularization after tracheal operation. We adopted an orthotopic canine tracheal transplantation model, close to the clinical setting, for the purpose of searching for this optimal dose in human beings. Although there was great variation in the doses of bFGF given to the various species of animals in the previously described three reports, we considered that the dose of bFGF should be determined as a proportion of surface area of the tracheal grafts. Klingbeil, Cesar, and Fiddes ${ }^{29}$ assessed an adequate dose of bFGF similarly, on the basis of wound surface area in a diabetic mouse model. The low doses $(0.01$ and 0.1 $\mu \mathrm{g} / \mathrm{cm}^{2}$ ) did not accelerate wound healing but both 1 and $10 \mu \mathrm{g} / \mathrm{cm}^{2}$ doses produced rapid wound closure. ${ }^{29} \mathrm{We}$, therefore, chose the doses of bFGF from 1 to $10 \mu \mathrm{g} / \mathrm{cm}^{2}$.

The mode of administration of bFGF is also problematic. It is important to retain bFGF at the surface of the organ for neovascularization. ${ }^{21-24}$ Thompson and colleagues ${ }^{21}$ induced angiogenesis by means of direct implantation of Gelfoam sponges (The Upjohn Co. of Canada, Don Mills, Ontario, Canada) treated with acidic fibroblast growth factor at the surface of the neck or peritoneum. However, 
Olech and associates ${ }^{25}$ failed to increase omental revascularization of tracheal transplants although the same Gelfoam product or Surgicel (Johnson \& Johnson Products Inc., New Brunswick, N.J.) was used as a reservoir to provide the trachea with long-term exposure to bFGF. Both limited application time and inadequate dosage may decrease the effects of bFGF on tracheal transplants. Mayer and colleagues $^{26}$ used a pump to provide a continuous supply of bFGF with favorable results. However, their approach is so clinically difficult that it may not be routinely accepted. Albes and associates ${ }^{27}$ obtained success by use of a deposit of bFGF in fibrin glue. Their approach is a clinically practical mode and leads to prolonged exposure time of the grafts to bFGF because fibrin glue gradually releases this agent. Fibrin glue itself also can enhance angiogenesis. ${ }^{30}$ We therefore used this application mode.

We designed this experimental model of tracheal autotransplantation for the purpose of determining the angiogenic potential of bFGF. The statistical analysis in this study may show trends alone because the number of animals in each group was inadequate for true significance to be demonstrated. Our results show that neither omentum alone nor omentum in combination with fibrin glue resulted in maintenance of the viability of long-segment tracheal autografts. These results supported our previous findings that only short-segment autografts maintain viability after revascularization with omental flaps. ${ }^{7,8}$ Fibrin glue did not enhance local revascularization of these 14-ring tracheal grafts. By contrast, all autografts that received the topical administration of $5 \mu \mathrm{g} / \mathrm{cm}^{2}$ bFGF showed good viability over a long period, as demonstrated by gross and histologic findings. Treatment with 5 $\mu \mathrm{g} / \mathrm{cm}^{2}$ bFGF may enhance vascular ingrowth from the omentum in the early posttransplant period and subsequently decrease ischemia in the middle part of the grafts. ${ }^{8}$ We believe that the optimal dose of bFGF for these tracheal grafts is probably $5 \mu \mathrm{g} / \mathrm{cm}^{2}$. Doses of $1 \mu \mathrm{g} / \mathrm{cm}^{2}$ may be too low to maintain the viability of long-segment tracheal grafts in light of our histologic findings, especially vessel number. Likewise, neither a bFGF dose of $10 \mu \mathrm{g} / \mathrm{cm}^{2}$ alone nor the same dose in combination with increased anatomic blood supply increased the vessel number of the grafts or maintained the structural integrity of the grafts when compared with a dose of $5 \mu \mathrm{g} / \mathrm{cm}^{2}$. In view of the interstitial histologic findings of proliferation of granulation tissue and fibrosis, at a dose of $10 \mu \mathrm{g} / \mathrm{cm}^{2}$ the negative effects of bFGF may outweigh its benefits. Moreover, the unusual pattern of unilateral proliferation of cartilage may be associated with tracheal malacia. Autografts treated with $10 \mu \mathrm{g} / \mathrm{cm}^{2}$ bFGF unexpectedly showed poor reepithelialization. The proliferation of granulation tissue seen at this dose of bFGF may impair reepithelialization. The observed correlation between epithelialization and vascularity may suggest that the acceleration of epithelial regeneration is caused by a revascularizing effect rather than a mitogenic effect of bFGF. ${ }^{24-26}$ In our preliminary study, almost all the epithelium was lost after devascularization. The remaining degenerated epithelium was chronologically restored to the normal respiratory epithelium after revascularization. ${ }^{7}$ The epithelial morphology is closely associated with vascularization.

We did not investigate very early revascularization after treatment with bFGF because the effects of bFGF on revascularization have been reported to occur only 7 to 14 days after its administration. ${ }^{22,26}$ The long-term effect of bFGF on graft viability is more important than its short-term effect. We have demonstrated that long-segment tracheal autografts treated with $5 \mu \mathrm{g} / \mathrm{cm}^{2}$ bFGF can maintain their long-term viability. Our results suggest that $b F G F$ may be useful in clinical trials for extensive tracheal reconstruction by transplantation. Additional study is required to evaluate the effect of bFGF on tracheal allografts in immunosuppressed hosts. We are now studying wound healing of the airway with the use of bFGF alone without omental wrapping and have obtained favorable results.

We conclude that treatment with fibrin glue enriched with $5 \mu \mathrm{g} / \mathrm{cm}^{2}$ bFGF in combination with omental wrapping may allow long-term viability of 14-ring tracheal autografts that the omentum alone could not maintain.

We thank Ms. Miki Kiyofuji for her expert technical assistance. KCB-1 was kindly supplied by Kaken Pharma Inc., Chiba, Japan. Beriplast P was kindly supplied by Höechist Inc., Tokyo, Japan.

REFERENCES

1. Grillo HC. Terminal or mural tracheostomy in the anterior mediastinum. J Thorac Cardiovase Surg 1966;51:422-7.

2. Pearson FG, Henderson RD, Gross AE, Ginsberg RJ, Stone $\mathrm{RM}$. The reconstruction of circumferential tracheal defects with a porous prosthesis: an experimental and clinical study using heavy Marlex mesh. J Thorac Cardiovasc Surg 1968;55:605-16.

3. Papp C, McCraw JB, Arnold PG. Experimental reconstruc- 
tion of the trachea with autogenous materials. J Thorac Cardiovasc Surg 1985;90:13-20.

4. Nakanishi R, Shirakusa T, Hanagiri T. Early histopathologic features of tracheal allotransplantation rejection: a study in nonimmunosuppressed dogs. Transplant Proc 1994;26:3715-8.

5. Nakanishi R, Yasumoto K, Shirakusa T. Short course immunosuppression after tracheal allotransplantation in dogs. $\mathrm{J}$ Thorac Cardiovasc Surg 1995;109:910-7.

6. Nakanishi R, Yasumoto K. Minimal dose of cyclosporin A for tracheal allografts. Ann Thorac Surg 1995;60:635-9.

7. Nakanishi R, Shirakusa T, Takachi T. Omentopexy for tracheal autografts. Ann Thorac Surg 1994;57:841-5.

8. Nakanishi R, Shirakusa T, Mitsudomi T. Maximum length of tracheal autografts in dogs. J Thorac Cardiovasc Surg 1993; 106:1081-7.

9. Folkman J, Klagsbrun M. Angiogenic factors. Science 1987; 235:442-7.

10. Nakanishi R, Shirakusa T. Tracheal reconstruction in 29 canines using allograft: a surgical technique (in Japanese). J Univ Occupational Environmental Health 1991;13:47-51.

11. Gospodarowicz D. Isolation and characterization of acidic and basic fibroblast growth factor. Methods Enzymol 1987; 147:106-19.

12. Cuevas $\mathbf{P}$, Burgos J, Baird A. Basic fibroblast growth factor (FGF) promotes cartilage repair in vivo. Biochem Biophys Res Commun 1988;156:611-8.

13. Kaplan E, Meier P. Non-parametric estimation from incomplete observations. J Am Stat Assoc 1958;53:457-81.

14. Peto R, Pike MC, Armitage $P$, et al. Design and analysis of randomized clinical trials requiring prolonged observation of each patient. Br J Cancer 1976;34:585-612.

15. Goldsmith HS, Griffith AL, Catsimpoolas N. Increased vascular perfusion after administration of an omental lipid fraction. Surg Gynecol Obstet 1986;162:579-83.

16. Morgan E, Lima O, Goldberg M, Ayabe H, Ferdman A, Cooper JD. Improved bronchial healing in canine left lung reimplantation using omental pedicle flap. J Thorac Cardiovasc Surg 1983;85:134-9.

17. Patterson GA, Todd TR, Cooper JD, et al. Airway complications after double lung transplantation. J Thorac Cardiovasc Surg 1990;99:14-21.

18. Khalil-Marzouk JF, Cooper JD. Allograft replacement of the trachea: experimental synchronous revascularization of com- posite thyrotracheal transplant. J Thorac Cardiovase Surg 1993;105:242-6.

19. Inui K, Schäfers HJ, Aoki M, et al. Effect of methylprednisolone and prostacyclin on bronchial perfusion in lung transplantation. Ann Thorac Surg 1993;55:464-9.

20. Gospodarowicz D. Localisation of a fibroblast growth factor and its effect alone and with hydrocortisone on $3 \mathrm{~T} 3$ cell growth. Nature 1974;249:123-7.

21. Thompson JA, Anderson KD, DiPietro JM, et al. Sitedirected neovessel formation in vivo. Science 1988;241:134952.

22. Eppley BL, Doucet M, Connolly DT, Feder J. Enhancement of angiogenesis by bFGF in mandibular bone graft healing in the rabbit. J Oral Maxillofac Surg 1988;46:391-8.

23. Gospodarowicz D, Ferrara N, Schweigerer L, Neufeld G. Structural characterization and biological functions of fibroblast growth factor. Endocrine Rev 1987;8:95-114.

24. O'Keefe EJ, Chiu ML, Payne RE Jr. Stimulation of growth of keratinocytes by basic fibroblast growth factor. J Invest Dermatol 1988;90:767-9.

25. Olech VM, Keshavjee SH, Chamberlain DW, Slutsky AS, Patterson GA. Role of basic fibroblast growth factor in revascularization of rabbit tracheal autografts. Ann Thorac Surg 1991;52:258-64.

26. Mayer E, Cardoso PFG, Puskas JD, et al. The effect of basic fibroblast growth factor and omentopexy on revascularization and epithelial regeneration of heterotopic rat tracheal isografts. J Thorac Cardiovasc Surg 1992;104:180-8.

27. Albes JM, Klenzner T, Kotzerke J, Thiedemann KU, Schäfers HJ, Borst HG. Improvement of tracheal autograft revascularization by means of fibroblast growth factor. Ann Thorac Surg 1994;57:444-9.

28. Kawaguchi H, Kurokawa T, Hanada K, et al. Stimulation of fracture repair by recombinant human basic fibroblast growth factor in normal and streptozotocin-diabetic rats. Endocrinology 1994;135:774-81.

29. Klingbeil CK, Cesar LB, Fiddes JC. Basic fibroblast growth factor accelerates tissue repair in models of impaired wound healing. Prog Clin Biol Res 1991;365:443-58.

30. Dvorak HF, Harvey VS, Estrella P, Brown LF, McDonagh J, Dvorak AM. Fibrin containing gels induce angiogenesis: implications for tumor stroma generation and wound healing. Lab Invest 1987;57:673-86. 